\title{
A Simple Model for Calc ulating Ballistic Missile Defense Effectiveness
}

\section{Dean A. Wilkening ${ }^{a}$}

This paper develops a probabilistic model that can be used to determine the technical performance required for a defense to meet specific political/military objectives. The defense objective is stated as a certain probability that no warheads leak through the defense. The technical performance is captured by the interceptor single-shot probability of kill and the warhead detection, tracking, and classification probability. Attacks are characterized by the number of warheads and undiscriminated decoys. Barrage and shoot-look-shoot firing modes are examined, with the optimal interceptor allocation derived for the shoot-look-shoot mode. Applications of this model for sizing national and theater missile ballistic missile defenses are discussed.

\section{INTRODUCTION}

In the current ballistic missile defense (BMD) debate, as with so many public policy debates, one must understand the connection between the resources devoted to a particular task and the objectives one wishes to accomplish.

Thus, the perennial question: "How much is enough?" In particular, "How much national or theater ballistic missile defense is required to accomplish specific political/military objectives, assuming a given level of technical performance for the defense?" Given the mounting political pressure within the United States to deploy both national and theater missile defenses in the coming decade, this question is of more than academic interest.

a Director of the Science Program, Center for International Security and Cooperation, Stanford University, Stanford, CA. 
However, since the technical performance of future ballistic missile defense systems is difficult to specify with any certainty, whereas plans exist for the size of possible future BMD deployments-for example, a national missile defense with either 20 or 100 interceptors located at a single site, and theater missile defenses with approximately 1,200 Theater High-Altitude Area Defense (THAAD) and/or 650 Navy Theater-Wide (NTW) upper-tier interceptors-this question is better turned around, namely, "What level of technical performance must defenses meet if existing programs are to meet useful political/military objectives?" This paper develops a simple BMD model to answer these questions and to provide a framework within which people can concretely compare their differing expectations about the effectiveness of BMD systems.

The paper begins with a short discussion of defense objectives. It then treats interceptor-based defenses as a Bernoulli trial problem. Next it examines the target kill probability-the main parameter in the Bernoulli trial model. The paper goes on to derive the size of the defense required to meet the defense performance criterion for barrage and shoot-look-shoot defense firing doctrines. The optimal interceptor allocation for shoot-look-shoot defenses is also presented. Finally, the paper gives two examples of how this model can be applied: first to national missile defense and then to theater missile defense. Cost has not been included in this model, although it could be added if one wants to examine the extent to which different defense objectives can be met within specific financial constraints.

One can image several plausible objectives for ballistic missile defense, e.g., completely blocking an attack of a given size, attenuating an attack by a certain percentage, or protecting some target set so that a specified fraction of the defended targets survive a given attack. The criterion chosen for this model is that the defense destroy all attacking warheads with a specified probability because the current ballistic missile defense debate is concerned largely with the proliferation of weapons of mass destruction. This is a very stringent criterion. The model can be adapted to a criterion that allows some leakage. However, the resulting formulas are more complex.

Therefore, for example, one might specify that a national missile defense completely block, with a probability of 0.80 , relatively small accidental and unauthorized attacks, or small intentional threats from hostile countries to which long-range ballistic missiles might proliferate in the future. According to the Ballistic Missile Defense Organization, U.S. national missile defense (NMD) systems should be designed to be effective against attacks ranging in size from 4 to 20 reentry vehicles, accompanied by varying levels of penetration aids. ${ }^{1}$ Moreover, NMD systems are supposed to meet the following crite- 
rion: 95 percent confidence of destroying 95 percent of the incoming attack, assuming four interceptors are fired at each incoming target. ${ }^{2}$ Interpreting this to mean a probability of 0.95 that no more than one out of 20 warheads leaks through the defense, this criterion is equivalent to a probability of 0.67 that no warheads leak through the defense for an attack containing 20 warheads, assuming the probability with which the defense destroys an attacking warhead is the same for all warheads in the attack.

The objective for theater missile defense is to defend U.S. and allied military forces and allied cities, the latter requiring the more stringent defense criterion. ${ }^{3}$ To the extent allied leaders rely on defenses to protect cities, instead of deterrence, they will demand very good defense performance. For example, theater missile defenses may be required to achieve a probability of 0.50 that no warheads land on allied cities. This may appear to be poor performance at first glance. However, it is a demanding criterion because it applies to the entire course of a hypothetical war, i.e., to the opponent's entire theaterrange ballistic missile arsenal, and not to a single attack as in the national missile defense example given above. Moreover, theater ballistic missile arsenals may contain between 50 and 200 missiles. ${ }^{4}$ Therefore, this criterion states that there should be no more than a 50-50 chance that a single warhead penetrates the defense even if the attacker's entire arsenal is launched at a single city. Such a defense would render theater-range ballistic missiles tactically useless and strategically marginal.

\section{DEFENSE AS A BERNOUW TRIAL PROBLEM}

It is difficult to calculate the effectiveness of BMD systems and, hence, the size of the defense required to meet specific performance criteria without a detailed understanding of the sensors and interceptors that make up the defense, as well as a detailed characterization of the targets the defense is attempting to shoot down. Nevertheless, one can develop a simple parametric model that will give approximate results using simple assumptions regarding the technical performance of the defense. This model, in turn, can be used to provide general observations about the level of technical performance that must be achieved if ballistic missile defenses are to provide militarily, if not politically, significant protection against nuclear, biological, and chemical threats. ${ }^{5}$

Ballistic missile attacks may contain warheads and decoys. Decoys may be partially discriminated from warheads depending on the warhead versus decoy signatures (e.g., infrared signatures, radar cross sections, etc.). Figure 1 


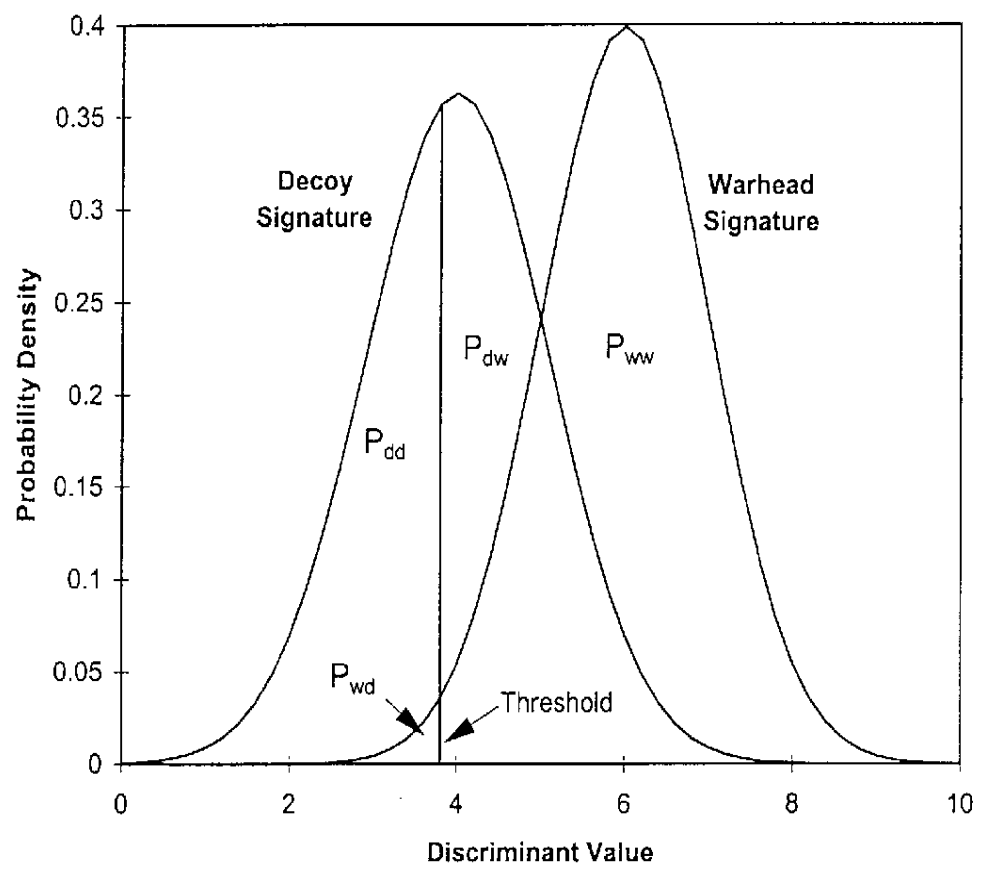

Figure 1: Decoy discrimination.

illustrates this situation for some threshold value of the discriminant for a case where decoy discrimination is relatively poor. In practice, the defense may have limited information regarding warhead and decoy signatures. Although estimates for some of these signatures may be calculated using basic physics, observations of an opponent's ballistic missile tests are required to obtain detailed information. However, observing an opponent's ballistic missile tests is not necessarily easy, especially for short-range missiles, as indicated by the U.S. Intelligence Community's failure to accurately monitor the August 31, 1998 North Korean Taepo Dong 1 launch that attempted to put a 
satellite into orbit. ${ }^{6}$ Moreover, ballistic missile proliferation may be accompanied by fewer tests and, hence, less accurate data compared to U.S. and Russian ballistic missile development programs. ${ }^{7}$ Faced with little information regarding likely warhead and decoy signatures, the defense may have to set the discriminant threshold quite low to ensure effective warhead detection, thereby compounding the decoy discrimination problem.

Nevertheless, in principle, one obtains four probabilities from Figure 1: the probability that a warhead is actually classified as a warhead, $P_{w w}$, i.e., the integral of the warhead signature to the right of the threshold; the probability that a warhead is classified as a decoy, $P_{w d}$, i.e., the integral of the warhead signature to the left of the threshold; the probability that a decoy is classified as a decoy, $P_{d d}$, i.e., the integral of the decoy signature to the left of the threshold; and the probability that a decoy is classified as a warhead, $P_{d w}$, i.e., the integral of the decoy signature to the right of the threshold. $P_{w d}$ represents Type I errors and $P_{d w}$ represents Type II errors in the decoy discrimination process. Note that $P_{w w}=1-P_{w d}$ and $P_{d d}=1-P_{d w}$. If there are $W$ warheads and $D$ decoys in the attack, the apparent number of warheads in the attack, $\mathrm{W}^{*}$, is given by

$$
W *=P_{w w} W+P_{d w} D
$$

i.e., this is the number of targets the defense must intercept.

There are two ways by which warheads can leak through the defense: (1) the warhead is classified as a warhead and is not shot down by the defense and (2) the warhead is classified as a decoy, in which case it gets a free ride. Obviously, the discriminant threshold should be set so as to make $P_{w d}$ as small as possible, recognizing that as the threshold is lowered more decoys will appear to be warheads (i.e., $P_{d w}$ increases). The probability, $q$, that a warhead leaks through the defense is given by

$$
\mathrm{q}=\mathrm{P}_{\mathrm{wd}}+\mathrm{P}_{\mathrm{ww}}\left(1-\mathrm{K}_{\mathrm{w}}{ }^{*}\right)=1-\mathrm{P}_{\mathrm{ww}} \mathrm{K}_{\mathrm{w}}{ }^{*}
$$

where $K_{w} *$ is the conditional probability that the defense shoots down a warhead given that it has been classified as a warhead. We now define

$$
\mathrm{K}_{\mathrm{w}}=\mathrm{P}_{\mathrm{ww}} \mathrm{K}_{\mathrm{w}} *
$$

where $K_{w}$ equals the probability that a warhead is detected and destroyed by the defense.

Defenses based on interceptors can be modeled as a Bernoulli trial prob- 
lem where the probability $\mathrm{P}(\mathrm{x})$ that $x$ attacking warheads (or missiles) will penetrate the defense is given by the binomial distribution,

$P(x)=\left(\begin{array}{c}W \\ x\end{array}\right) q^{x}(1-q)^{W-x}=\left(\begin{array}{c}W \\ x\end{array}\right)\left(1-K_{w}\right)^{x}\left(K_{w}\right)^{W-x}=\frac{W !}{x !(W-x) !}\left(1-K_{w}\right)^{x} K_{W}{ }^{W-x}$

where $K_{w}$ is assumed to be the same for all warheads and $W$ is the number of warheads in the attack. For the case where the defense shoots down all warheads, i.e., $x=0$, this reduces to

$$
P(0)=\left(K_{w}\right)^{W}
$$

as one might expect. Figure 2 shows a plot of this probability as a function of the number of warheads in the attack for different values of $K_{w}$. If the criterion for defense performance states that the number of warheads that leak through the defense must be less than or equal to $L$, the probability with which this occurs is given by

$$
P(\leq L)=\sum_{x=0}^{L} P(x)
$$

\section{TARGET KIL PROBABIUTY}

The probability with which a single attacking warhead or target can be destroyed is given quite generally by the equation:

$K_{j}=\left[1-P_{j}(\right.$ common mode failure $\left.)\right] P_{j}(k i l l \mid$ no common mode failure),

where $K_{j}$ is the probability that a target of type ${ }_{j}$ (i.e., warhead or decoy) is destroyed, $\mathrm{P}_{\mathrm{j}}$ (common mode failure) is the probability that some common mode failure affects all shots taken at the target, and $\mathrm{P}_{\mathrm{j}}$ ( $\mathrm{kill} \mid$ no common mode failure) is the probability that the defense can shoot down target type $\mathrm{j}$ if no common mode failures occur.

Examples of common mode failures are a failure to detect and accurately track the target, misclassifying a warhead as a decoy, and the BMD command and control system reliability (i.e., a failure to transmit the target track data to 


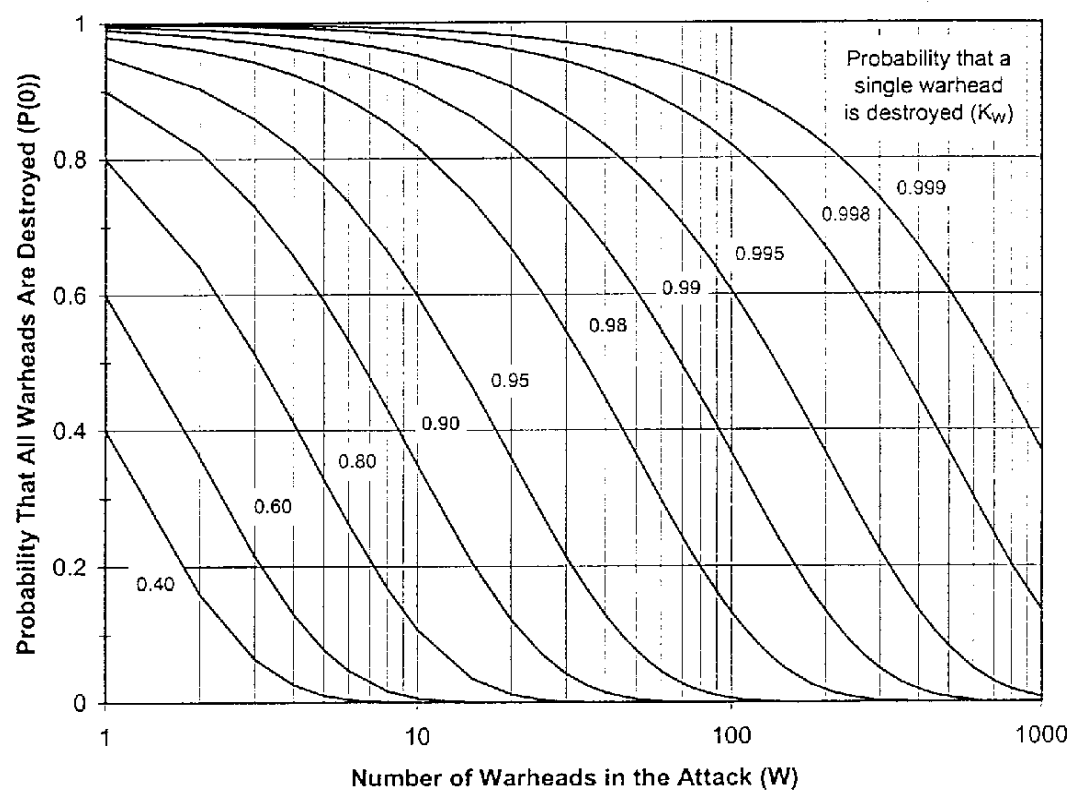

Figure 2: Probability That all Warheads a re Destroyed vs. Attack Size.

the defense interceptors). ${ }^{8}$ The target kill probability can be rewritten as

$$
K_{j}=P_{j}(\text { track }) P_{j}(\text { kill } \mid \text { track })
$$

where all sources of common mode failure have been included in Pj(track), i.e.,

$$
\mathrm{P}_{\mathrm{j}}(\text { track })=\mathrm{P}_{\text {det\&track }} \cdot \mathrm{P}_{\text {classify }} \cdot \mathrm{P}_{\text {rel }}
$$


where $P_{\text {det\&track }}$ is the probability of detecting and successfully tracking a target with sufficient precision to commit a defense interceptor, $P_{\text {classify }}$ is the probability that the warhead or decoy is classified as a warhead (i.e., $P_{w w}$ for warheads and $P_{d w}$ for decoys), and $P_{r e l}$ is that part of the defense system reliability that affects all shots taken by the defense.

The conditional probability that target type $\mathrm{j}$ is destroyed if successfully tracked $P_{j}(k i l l \mid$ track), is given by

$$
P_{j}(k i l l \mid \text { track })=1-\left(1-k_{j 1}\right)\left(1-k_{j 2}\right) \ldots\left(1-k_{j n}\right)
$$

for a defense that fires multiple interceptors at each target, where $k_{j i}$ is the conditional single-shot probability of kill (SSPK) for target type j associated with the $\mathrm{i}^{\text {th }}$ shot, given that all prior shots have failed to destroy the target. The total number of shots taken at each target of type $\mathrm{j}$ is given by $\mathrm{n}$. $\mathrm{N}$ ote that this equation is valid if the shots are statistically dependent. Statistical dependence may occur for several reasons. F or example, if the $i^{\text {th }}$ shot does not destroy the target but knocks it off course or changes its signature, then subsequent shots may have a greater or lesser chance of destroying the target. Or, if multiple shots are taken at incoming targets, the SSPK of subsequent shots may degrade because the fire control radar cannot track and communicate with a large number of interceptors simultaneously during their flyout. If multiple targets enter the defense radar coverage simultaneously, this problem gets worse. ${ }^{9} \mathrm{~F}$ inally, this equation assumes the interceptor SSPK is uniform throughout the defended area or defense "footprint," which may not al ways be the case because the SSPK may degrade the farther the interceptor must fly to its target.

If one assumes the shots are statistically independent with identical SSPKs, the above equation reduces to

$$
P_{j}(\text { kill } \mid \text { track })=1-\left(1-k_{j}\right)^{n}=1-1_{j}^{n}
$$

where $k_{j}$ is the SSPK associated with each shot at target type $\mathrm{j}, \mathrm{l}_{\mathrm{j}}=1-\mathrm{k}_{\mathrm{j}}$ is the leakage rate associated with each shot, and $n$ is the number of shots taken at each target of type j. The same formula can be applied as an approximation for statistically dependent shots if $l_{j}$ is defined to be the geometric mean of the leakage rate for the statistically dependent shots. Therefore, the defense kill probability, $k_{j}$, can be written as

$$
\mathrm{K}_{\mathrm{j}}=\mathrm{P}_{\mathrm{j}}(\operatorname{track})\left[1-\left(1-\mathrm{K}_{\mathrm{j}}\right)^{\mathrm{n}}\right]=\mathrm{P}_{\mathrm{j}}(\operatorname{track})\left(1-\mathrm{I}_{\mathrm{j}}^{\mathrm{n}}\right)
$$


The existence of common mode failures implies that unlimited improvements in defense effectiveness cannot be achieved simply by using more interceptors.

Current BMD designers apparently expect interceptor SSPKs around 0.80 to $0.85 .{ }^{10}$ While this may not be unrealistic for unitary warheads without countermeasures, such high SSPKs may be difficult to achieve in the presence of countermeasures-although it is also difficult to assess how low the SSPK might drop. The SSPK against decoys is likely to be different than that for warheads, depending on the type of decoy. Similarly, if one is optimistic about emerging sensor technologies, sensor architectures should be possible against simple ballistic missile threats that have values for $\mathrm{P}$ (track) above 0.95, and perhaps above 0.99. ${ }^{11}$ Again, the important question is how high $\mathrm{P}$ (track) might be in the presence of enemy countermeasures.

\section{Countermeasures}

One of the most significant recent advances with respect to ballistic missile defense is the advent of hit-to-kill interceptors. This is the critical technology upon which most new BMD interceptors rely. The other critical BMD technologies are radar and infrared sensors for missile and warhead detection, tracking, and decoy discrimination. Over the past decade, advances in radar (e.g., "imaging" radar with very good range resolution) and optical sensors (e.g., long-wave infrared sensors) may make it possible to discriminate some decoys and booster fragments from warheads, especially when data from both sensor types are combined. Nevertheless, decoy discrimination probably remains the greatest technical challenge for effective ballistic missile defense.

Countermeasures to ballistic missile defenses can be grouped into the following categories: circumvention (i.e., using delivery means other than ballistic missiles), defense suppression (i.e., attacking the defense directly), saturation (using a large number of ballistic missiles or decoys), and qualitative improvements in the offense (e.g., reduced missile or warhead signatures). The model discussed in this paper can accommodate parametrically the latter two, and non-destructive forms of defense suppression (i.e., jamming). In particular, countermeasures are grouped in the model according to whether they reduce the probability of successful target detection and tracking (thereby delaying the launch of the interceptor and causing the defended footprint to shrink, or causing it not to be launched at all), reduce the interceptor SSPK after it is launched, or simply overwhelm the defense with too many targets. Examples of countermeasures that reduce P(track) are stealth techniques that reduce the target radar cross section, radar or infrared (IR) jammers that increase sensor noise levels, and large attacks that converge on the 
192 Wilkening

defense simultaneously, thereby saturating the tracking and fire control capabilities of the defense (i.e., saturating the defense "battle space").

Countermeasures that reduce exoatmospheric interceptor SSPKs are techniques for cooling the warheads so hit-to-kill IR seekers cannot lock onto their targets (cool warheads heat up upon reentry) and encapsulating warheads in large balloons, thereby obscuring the precise warhead location so hitto-kill interceptors miss their true targets. Maneuvering warheads may reduce endoatmospheric interceptor SSPKs. ${ }^{12}$

Finally, the defense may be saturated with a large number of decoys that cannot be discriminated from warheads (i.e., large values of $P_{d w} D$ ), a large number of multiple independently targeted reentry vehicles (MIRVs) for nuclear-tipped long-range missiles, or a large number of chemical or biological weapon (CBW) submunitions. Fractionated CBW payloads pose one of the most difficult responsive threats to theater missile defenses because tens or hundreds of bomblets may be deployed on each missile. CBW submunitions are more challenging for long-range ballistic missiles because it is difficult to provide sufficient thermal protection to prevent CBW agents from denaturing due to reentry heating. CBW submunitions also are difficult to detect and track because of their small radar cross section and, if tracked, may be difficult to intercept with hit-to-kill interceptors after their release because of their small size. ${ }^{13}$ Booster fragments may also appear as exoatmospheric decoys although, as mentioned above, imaging radars may be able to discriminate some of these from warheads.

The 1991 Gulf War provided an example of BMD countermeasures when booster fragments and unintentional maneuvering on the part of poorly designed Al Hussayn missiles undermined Patriot (PAC-2) defense effectiveness. The PAC-2 SSPK apparently was much lower than originally estimated, i.e., in the range $0.09-0.25$ and possibly lower, demonstrating that battlefield surprises may lower the SSPK below what one expects based on engineering estimates and test data alone. ${ }^{14}$

It is important to note that the current theater ballistic missile threat is believed to consist largely of unitary warheads since no intentional countermeasures were used on I raqi ballistic missiles during the Gulf War and none have been observed in theater ballistic missile tests since, at least among developing states (although such tests may have gone unnoticed). ${ }^{15} \mathrm{~N}$ or is it clear when decoys or other countermeasures might appear, although it seems reasonable to assume they will because these countermeasures, while not trivial, are probably within reach of most countries that have the ability to produce ballistic missiles indigenously. For example, one assessment claims that modest trajectory shaping (depressed or elevated), simple exoatmospheric 
decoys or chaff, missiles or missile warheads that intentionally perform barrel roll maneuvers within the atmosphere, and low-power el ectronic countermeasures designed to jam radar-guided homing interceptors may be possible before 2010, while noting that more sophisticated decoys that mimic radar and infrared reentry vehicle signatures (especially during reentry), stealthy missiles or reentry vehicles, sophisticated endoatmospheric maneuvering (especially for a separated warhead), electronic countermeasures against ground-based radars, and multiple warheads such as CBW submunitions appear beyond the technical capability of emerging ballistic missile states, at least in the Middle East. ${ }^{16}$

In any case, the outcome of the long-term defense-offense measure-countermeasure competition is difficult to determine. On the one hand, the offense frequently has the last move, suggesting that modestly sophisticated adversaries might be able to develop simple countermeasures after defenses are deployed. Moreover, surprises of the sort that occurred during the Gulf War are always possible. On the other hand, the U nited States has superior technical and financial resources relative to most regional opponents. Therefore, if the United States improves its missile defenses over time against known countermeasures as well as against ones developed by U.S. "red teams," it is possible that the resulting defenses might be robust to the sorts of countermeasures North Korea, Libya, Syria, Iraq, and Iran might be able to deploy, although this is unlikely to be true for Russian or Chinese countermeasures, or for states that receive substantial assistance from Russia or China. For example, tests with two prototype NMD exoatmospheric kill vehicles reportedly discriminated "decoys, light replicas, and penetration aides," more sophisticated than the ones emerging ballistic missile states could deploy, from actual reentry vehicles-although this claim is difficult to substantiate. ${ }^{17}$ In addition, the United States and Great Britain took years to develop countermeasures that were believed to be effective against the relatively unsophisticated radars in the Moscow ABM system. ${ }^{18}$ U.S. sensor architectures not only include infrared sensors, but also multiple radar sites which aid decoy discrimination by providing multiple viewing angles on the target.

A definitive technical assessment of these countermeasures and BMD counter-countermeasures is beyond the scope of this paper. Suffice it to say that the effectiveness of BMD systems against simple threats (i.e., unitary warheads) may be fairly good, assuming adequate testing can solve the engineering problems that plague current-generation hit-to-kill interceptors. However, BMD effectiveness against future threats is less certain and will depend largely on the ability to defeat offensive countermeasures of the sort mentioned above. The impact of countermeasures is captured in the following 


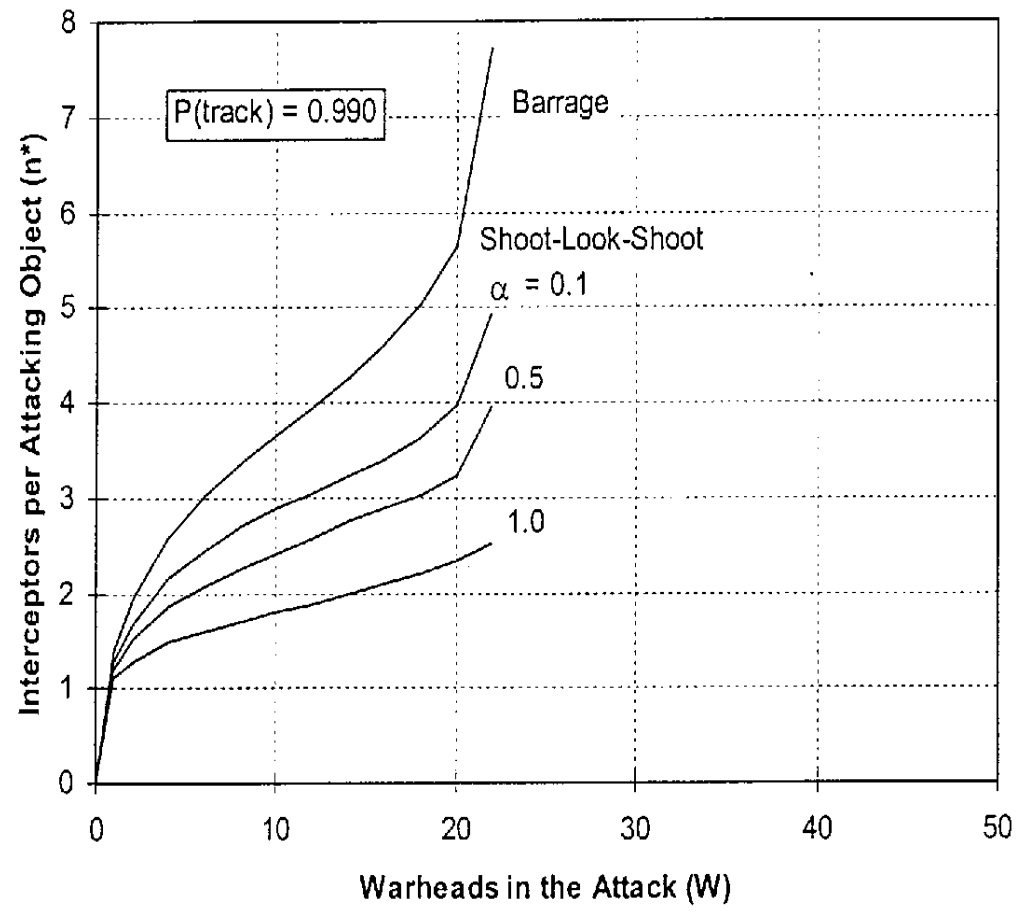

Figure 3: Interceptors Allocation vs. Attack Size $(P(\operatorname{track})=0.99$, SSPK $=0.7)$.

analysis by analyzing the variation in defense effectiveness as a function of parametric variations in the warhead detection and tracking probability, the interceptor SSPK, and the number of decoys that cannot be discriminated from warheads. 


\section{DEFENSE REQUIRED TO MEET PERFORMANCE CRITERION}

F rom the proceeding, one can derive the number of shots that must be fired at each incoming warhead to achieve a given level of defense effectiveness. The details of the calculation are explained in the Appendix. Figure 3 illustrates the minimum number of interceptors required per apparent warhead, as a function of the number of attacking warheads for different fractions $\alpha$ (the fraction of apparent warheads that are actually warheads). The number of interceptors per apparant warhead are shown for barrage and shoot-lookshoot firing doctrines. In barrage fire, $\mathrm{n}$ interceptors are fired near simultaneously at each incoming target. In shoot-look-shoot, one interceptor typically is launched against each incoming target, then the remaining shots are directed only at those warheads and decoys that are not destroyed in the first shot opportunity. The interceptor single-shot kill probability in Figure 3 is assumed arbitrarily to be 0.7 for warheads and one-third this value for decoys, $\mathrm{P}$ (track) equals 0.99 , and the defense criterion is a 0.80 probability that no warheads leak through the defense. The graphs stop for attacks larger than 22 warheads because the criterion that all warheads must be shot down with a probability of 0.80 cannot be met. Figure 4 shows the same set of curves for near-perfect detection, tracking, and warhead classification (i.e.,

$P($ track $)=0.999)$. Note that shoot-look-shoot firing doctrines become less effective as more undiscriminated decoys are included in the attack. In fact, in the limit where $k_{d} \rightarrow 0$ and $D \rightarrow \infty$, the optimal shoot-look-shoot case is equivalent to the barrage case, as one might expect.

\section{LAYERED DEFENSES}

Layered defenses with separate defense systems and independent detection and tracking sensors in each layer can, in principle, achieve very high defense effectiveness. If one assumes common mode failures between layers are negligible (there are few ways to test this under realistic wartime conditions), then the effectiveness of a defense with $m$ layers is

$$
\mathrm{K}_{\mathrm{w}}=1-\mathrm{L}_{1} \mathrm{~L}_{2} \ldots \mathrm{L}_{\mathrm{m}}
$$

where $L_{i}$ is the probability that a warhead leaks through the $i^{\text {th }}$ layer of the defense. ${ }^{19} \mathrm{~F}$ or example, if one assumes the target kill probability is 0.97 in 


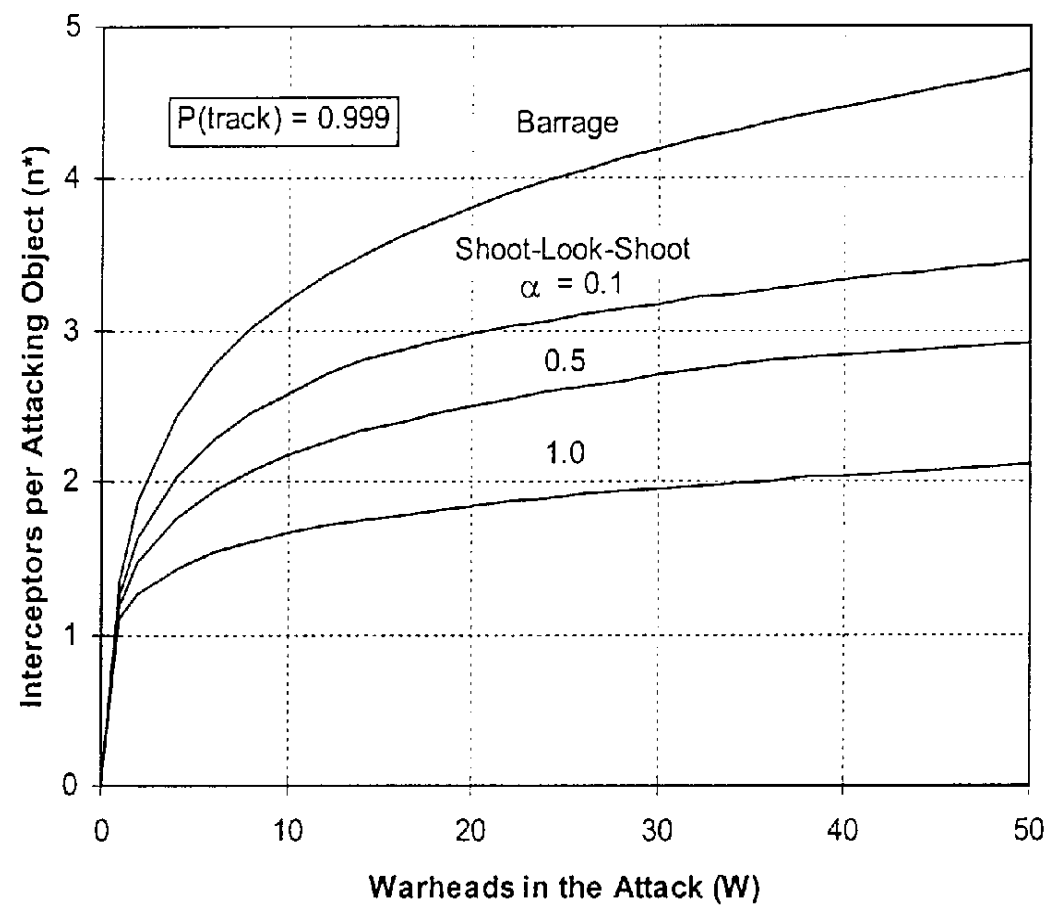

Figure 4: Interceptors Allocation vs. Attack Size $(P($ track $)=0.999$, SSPK $=0.7)$.

each of two layers, then the overall probability that a target can be destroyed is approximately 0.999 , implying that such a defense could, in principle, block 100 out of 100 warheads with a probability of 0.9 (see Figure 2 ).

\section{APPUCATIONS}

To answer the question "How much ballistic missile defense is enough?" one must address two questions: how many BMD sites does it take to adequately 


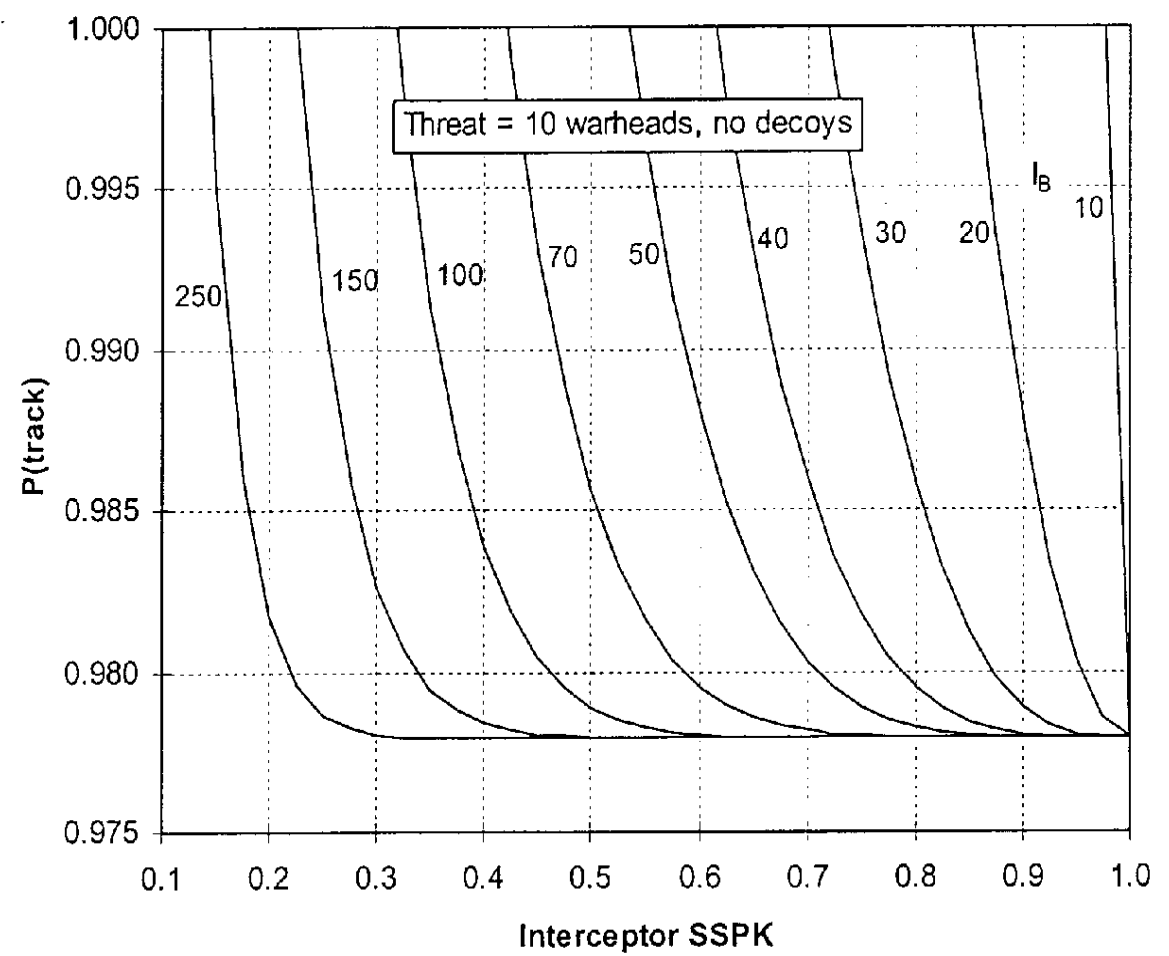

Figure 5: NMD Interceptors (Barrage) vs. P(track) and SSPK.

cover the territory of interest and how many interceptors should be deployed at each site to meet the defense performance criterion? The number of BMD sites required depends on the BMD footprint, which is a function of the interceptor flyout speed and the time available for interceptor flyout, the latter of which is a function of the speed of the incoming target and the radar detection range. The radar detection range, in turn, is a function of the radar poweraperture product, the target's radar cross section, and the number of targets than must be engaged simultaneously. Shoot-look-shoot footprints are smaller that barrage footprints because less flyout time is available for the second shot 
attempt. Again, this model assumes that the interceptor SSPK is uniform throughout the defended footprint and that the footprint does not shrink appreciably with the attack sizes considered here. Finally, since the SSPK and $\mathrm{P}$ (track) for future defense systems is highly conjectural, the applications of the model discussed in this section will start by assuming some nominal BMD deployment, then ask how well this system must work technically to provide meaningful defense.

\section{NATIONAL MISSILE DEFENSE}

If the United States decides to deploy a thin NMD system after the J une 2000 Deployment Readiness Review, the system will be deployed in several phases. The initial deployment likely will consist of 20 NMD interceptors deployed at a single site either in central Alaska or at Grand Forks, North Dakota by 2005, the second phase deployment may consist of up to 100 NMD interceptors at a single site by 2010 , and the third phase deployment potentially will consist of 125 interceptors deployed at two sites by 2015 for a total of 250 interceptors. ${ }^{20}$ All of these NMD deployment options violate the ABM Treaty in varying degrees. ${ }^{21}$ Whether Russia will agree to amend the ABM Treaty to allow such deployments remains to be seen. Nevertheless, assuming the ABM Treaty is either modified or abrogated and the United States goes ahead with a NMD deployment, one can calculate the technical performance this defense must have to provide meaningful protection. For the multisite NMD option, one must keep in mind that the attacker can concentrate his attack against targets located within a single defended area to saturate the defense.

For illustrative purposes we assume a threat of 10 warheads without decoys (initially) and that the defense performance criterion is to destroy all 10 warheads with a probability of 0.8 . Figure 5 illustrates how the number of NMD interceptors required to meet this performance criterion varies as a function of $\mathrm{P}$ (track) and the interceptor SSPK, assuming a barrage firing doctrine. Note that the defense cannot meet the performance criterion if $\mathrm{P}$ (track) is below 0.978, regardless of the interceptor SSPK or how many shots are fired. For a barrage firing doctrine the number of shots taken at each warhead is constant along each of the NMD interceptor contour lines. For example, along the 40 interceptor contour, four shots are taken at each warhead. While taking more shots at an incoming target reduces the SSPK required per shot, there are limits to the number of interceptors that can be launched simultaneously to avoid saturating the defense battle space. Four 


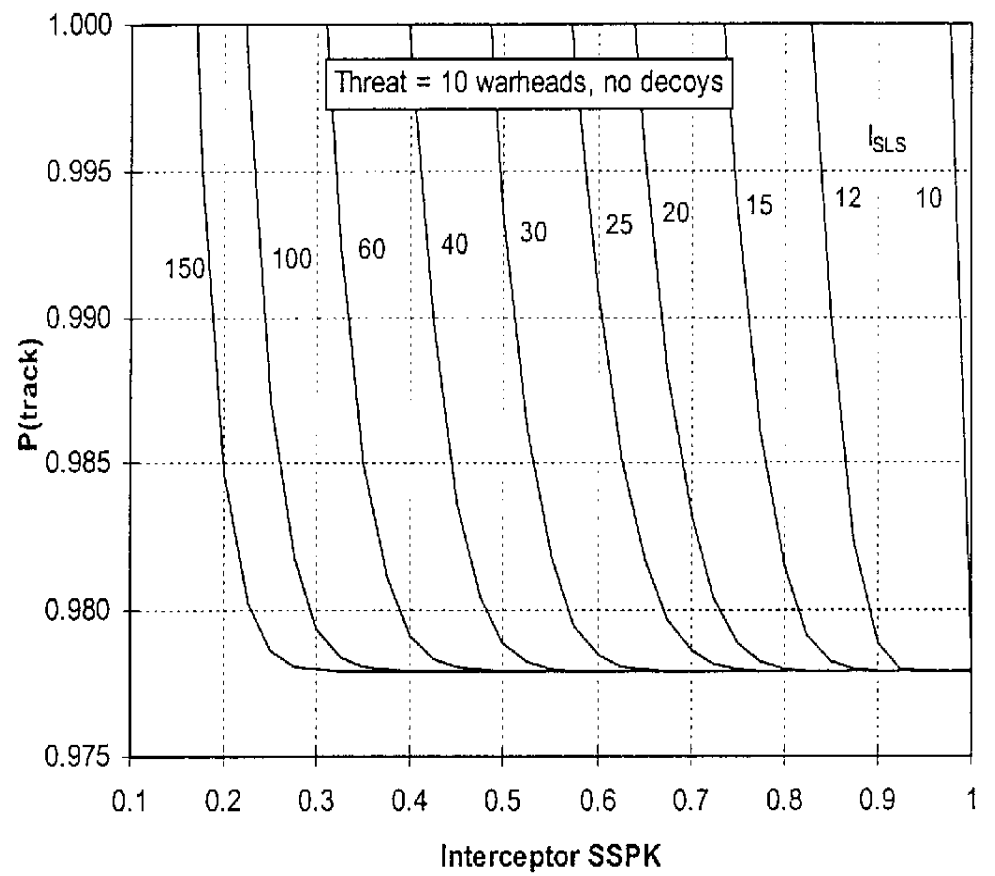

Figure 6: NMD Interceptors (Shoot-Look-Shoot) vs. P(track) and SSPK.

shots per target is a reasonable upper bound.22 Therefore, the required technical performance for the 20-interceptor and 100-interceptor defenses correspond to any values of SSPK and P (track) to the right of the 20-interceptor and 40-interceptor contour lines, respectively, i.e., interceptor SSPKs above approximately 0.92 and 0.70 , respectively, for a value of $\mathrm{P}$ (track) above 0.985 .

New figures must be drawn for attacks with different numbers of warheads. If decoys are included in the attack, the required technical performance for the defense can be read off figures like Figure 5, but one must remember to 
multiply the number of NMD interceptors al ong each contour line by $\mathrm{W} * \mathrm{~W}$ to get the actual number of interceptors required to meet the defense performance criterion in the presence of decoys. For example, if two high-quality decoys are included for each warhead in a 10-warhead attack, i.e., the attack contains 30 apparent warheads, then a 100-interceptor defense would have to have values of SSPK and P(track) to the right of a 33-interceptor contour line in Figure 5 if the defense is to shoot down all 10 real warheads with a probability of $0.80 . .^{23}$

Figure 6 illustrates the same variations for a shoot-look-shoot firing doctrine, again for an attack containing 10 warheads and no decoys. In this figure the number of shots taken at each incoming warhead is not constant along the interceptor contour lines. Moreover, the optimal number of shots taken in the first shot opportunity varies across the domain, with one shot taken in the first shot opportunity approximately between the 10-interceptor and 25-interceptor contour lines, two shots in the region between the 25 -interceptor and 40-interceptor contour lines, three shots between the 40-interceptor and 100interceptor contour lines, and four or more shots to the left of the 100-interceptor contour line. If decoys are included in the attack, this plot must be recalculated with some assumptions made about the SSPK against decoys. If the SSPK against decoys is the same as for warheads, then the required technical performance can be obtained simply by multiplying the interceptor contour lines in Figure 6 by $W^{*} M$ to get the actual number of interceptors required to meet the defense performance criterion, as was done for a barrage firing doctrine. Finally, a single-site NMD system cannot cover the continental United States with a shoot-look-shoot firing doctrine. Typically, four to nine sites are required. ${ }^{24}$ Hence, the total number of interceptors deployed nationwide is four to nine times the numbers given in Figure 6. Comparing this to the interceptor levels for barrage fire shown in Figure 5, one observes that a shoot-look-shoot firing doctrine does not appear to be more effective for a thin national missile defense, especially when one considers the technical difficulty providing reliable kill assessment prior to firing the second shot(s).

\section{THEATER MISSILE DEFENSE}

TMD systems have smaller defended footprints due to shorter flight times for theater-range ballistic missiles and slower TMD interceptor speeds. Hence, several sites typically are required to achieve adequate coverage. F or example, a recent U.S. Department of Defense estimate states that four THAAD batteries would be required to cover South Korea and six to cover J apan (or only four 
if three additional THAAD radars are included in the architecture) with a barrage firing doctrine. ${ }^{25}$ The northern areas of South Korea (including Seoul) require lower-tier defenses because the $40 \mathrm{~km}$ minimum intercept altitude assumed for THAAD precludes intercepts against short-range North Korean missiles that can threaten this region. A similar number of THAAD batteries (i.e., approximately ten) would be required to cover important areas within the Persian Gulf. The coverage obtained with the NTW upper-tier defense depends on the location of the NTW ship relative to the ballistic missile launch location, the sensor support, and the flyout speed of the NTW interceptor. The most favorable scenario is coverage of J apan because NTW ships can be stationed between the threat (North Korea) and the territory being defended. In fact, NTW ships located in the middle of the Sea of J apan might be able to engage North Korean missiles in their ascent phase, thereby giving very large defended footprints behind the ship. A single NTW ship should be able to defend all of J apan assuming a 4-4.5 km/sec interceptor flyout speed. ${ }^{26}$ Defending South Korea requires an additional NTW ship, although NTW interceptors cannot cover the northern two-thirds of South Korea because they cannot engage short-range (e.g., Scud B) missiles because they fly beneath the minimum NTW intercept altitude (approximately $70 \mathrm{~km}$ ). NTW coverage in the Persian Gulf would be more difficult due to the lack of accessible waters.

The number of THAAD or NTW upper-tier interceptors required at each site can be calculated once the architecture is specified. For illustrative purposes, a layered defense with THAAD or NTW operating as an upper-tier and PAC-3 as a lower-tier defense is assumed, where both layers are assumed to be equally effective, i.e., the upper and lower tiers are assumed to have the same interceptor SSPK and the same value for P(track) (i.e., the leakage rate for each layer is assumed to be the same). While this generally will not be the case, this assumption allows one to observe how the required number of upper-tier interceptors varies with the overall technical performance of the defense. In addition, both layers are assumed to operate only in barrage mode (to achieve wide area coverage for the upper tier and because insufficient time exists for the lower tier to operate in anything but barrage mode). Therefore, this layered architecture provides a thin area defense over the entire theater with selected high-value targets protected by both upper and lower-tier defenses.

The required number of THAAD upper-tier interceptors, operating in a barrage mode, to ensure that no warheads leak through the upper and lower tiers with a probability of 0.5 is shown in Figure 7 for an attack containing 100 


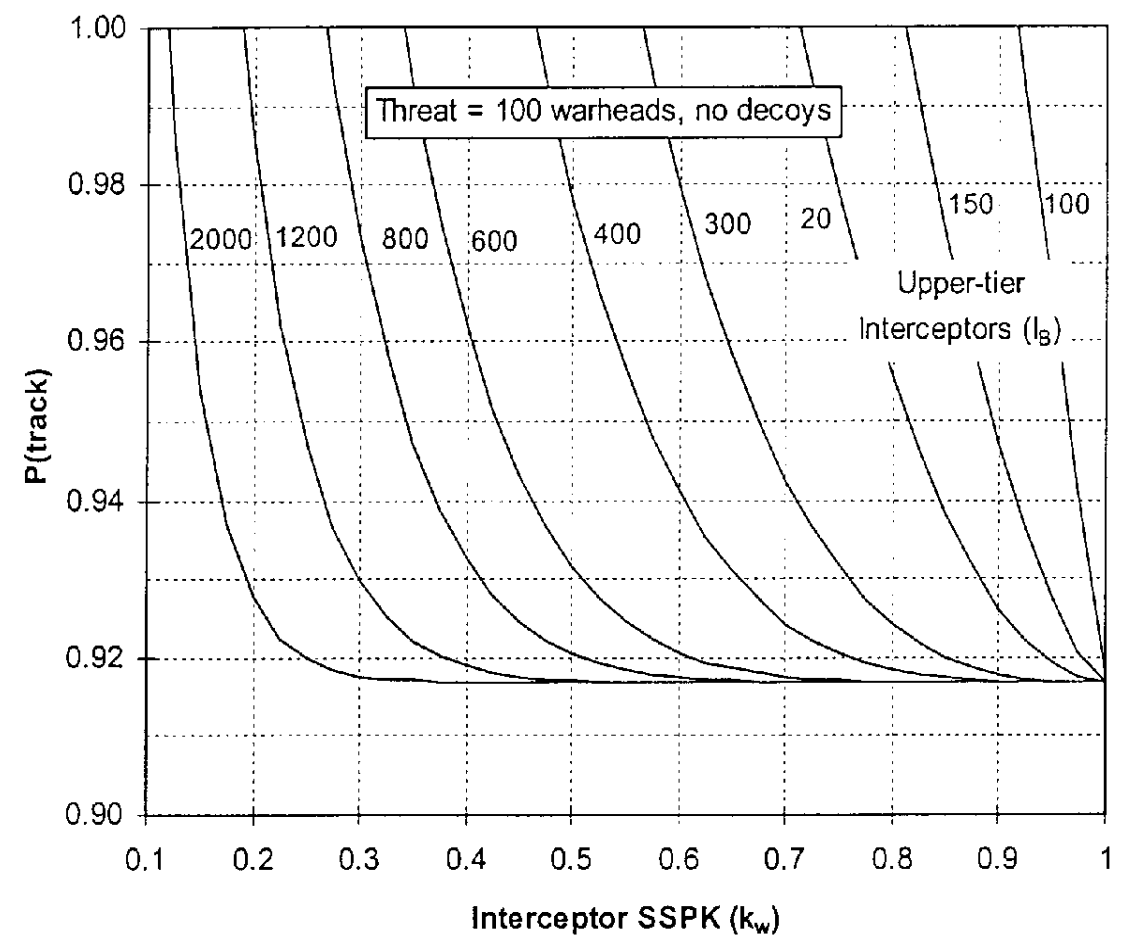

Figure 7: THAAD Interceptors (Barrage) vs. P(track) and SSPK.

warheads as a function of the SSPK and P(track) assumed for the upper and lower tiers. The number of PAC-3 interceptors required in the lower tier has not been calculated. Generally, it will be far less than the number of upper-tier interceptors. If decoys are included in the attack, the interceptor numbers must be multiplied by $\mathrm{W} * W$, assuming the SSPK for interceptors and decoys is the same in both layers. If one again assumes that no more than four interceptors can be fired at each incoming target to avoid battle space saturation, then the upper and lower-tier technical performance must lie in the domain to the right of the 400 -interceptor contour line in Figure 7, i.e., THAAD (or NTW) 
and PAC-3 interceptor SSPKs would have to be above approximately 0.60 and detection and tracking probabilities would have to exceed 0.94 , for the defense to be effective. TMD planners apparently hope for a THAAD SSPK as high as $0.80-0.85 .{ }^{27}$ Finally, a critical assumption behind Figure 7 is that no common mode errors occur between the upper and lower tiers. If common mode errors exist, they must be below approximately 0.1 percent for this figure to remain valid.

The assumption that all interceptors can engage an incoming attack is equivalent to assuming the opponent spreads its attack uniformly over all defended areas. However, against a multisite defense the opponent likely will concentrate the attack to saturate a few defended sites, with the constraint that not all ballistic missiles in the inventory can reach all defended areas due to range limitations and not all ballistic missiles can be launched in a single day because of insufficient mobile launchers. While Scud-type mobile missiles can be reloaded within several hours, few mobile launchers will be able to launch more than one missile per day because of the need to move and hide immediately after launch to avoid U.S. air attacks. ${ }^{28}$ Consequently, each defended site must have enough interceptors to handle the maximum number of missiles that can be launched in a salvo, i.e., a number equal to the number of mobile launchers, on the assumption that subsequent attacks can be handled by replenishing interceptors at the site(s) being exhausted within less than 24 hours from storage sites in theater. Historically, countries have deployed between 4 to 15 ballistic missiles per mobile launcher, suggesting that at most 6-25 percent of the arsenal can be launched in a single day. ${ }^{29} \mathrm{~F}$ or example, Russia deployed four missiles with each Scud B mobile launcher. I raq had approximately 15 Al Hussayn missiles per mobile launcher prior to the 1991 Gulf War and, in fact, launched a maximum of 6 percent of its arsenal in a single day. ${ }^{30}$

Therefore, if four THAAD sites are required to cover J apan from No Dong and Taepo Dong missiles and North Korea can launch at most 10 percent of this arsenal in a single day, then the total number of interceptors that must be deployed to the theater to guarantee that no single site can be saturated by salvo launches is equal to 1.3 times the number of interceptors given in Figure $7 .{ }^{31}$ Consequently, if North Korea has 100 Scud B/C missiles and 100 No Dong/ Taepo Dong missiles in its inventory, then 520 THAAD missiles would have to be deployed at four sites in South Korea and 520 THAAD missiles at four sites in J apan to ensure than no warhead penetrates the upper and lower tiers with a probability of 0.5 for either country-assuming the technical performance for both tiers is to the left of the 400-warhead contour in Figure 7 for Scud B/C and No Dong/Taepo Dong missiles, i.e., interceptor SSPKs above approxi- 
mately 0.6 and detection and tracking probabilities above approximately 0.94 , and that four interceptors are launched at each target. The NTW system also must have a technical performance to the right of the 400-interceptor contour line in Figure 7 for a 100-warhead No Dong/Taepo Dong threat to J apan. However, the offense cannot concentrate the attack to saturate the defense because a single NTW site covers all of J apan. Therefore, only 400, instead of 520, NTW interceptors would have to be deployed to defend J apan from the maximum salvo launch. Finally, if the attack contains decoys that cannot be discriminated by the defense, the number of interceptors required to meet the defense performance criterion can be obtained by multiplying the number of interceptors along any given contour line in $\mathrm{F}$ igure 7 by the ratio $\mathrm{W} * \mathrm{~W}$ to get the number of interceptors required to meet the defense performance criterion in the presence of decoys.

\section{CONCLUDING OBSERVATIONS}

This paper models interceptor-based ballistic missile defenses as a Bernoulli trial problem wherein the technical performance of the defense is captured by several parameters: the interceptor SSPK, the warhead detection, tracking, and classification probability $\mathrm{P}$ (track), and the ratio of apparent to real warheads in the attack (i.e., W*/W ). This model can be used to calculate "How much ballistic missile defense is enough?" once trusted values for these parameters are given. However, since the technical performance of future BMD systems is highly conjectural, this model has been used to understand the technical performance current BMD programs must meet if they are to achieve useful defense objectives. For example, a 100-interceptor NMD system based at a single site and operating in barrage mode with no more than four interceptors fired at any incoming target must achieve values of $\mathrm{P}$ (track) above 0.985 and interceptor SSPKs above 0.7 if it is to block attacks containing up to 10 warheads accompanied by an average of 2.5 undiscriminated decoys per warhead. In addition, this model demonstrates that shoot-lookshoot firing doctrines probably are not cost-effective for a thin national missile defense because they require approximately the same number of interceptors as a barrage firing doctrine for equal effectiveness since they require more sites for adequate coverage, and they require effective kill assessment after the first shot.

Theater missile defenses will face larger threats. Hence, they must have multiple layers each with its own sensors and interceptors, especially for protecting high-value targets such as allied cities. If upper and lower-tier TMD systems are to protect allied cities from ballistic missile arsenals containing up to 100 unitary nuclear, biological, or chemical warheads, then upper and 
lower tier interceptors must have SSPKs above approximately 0.6 with warhead detection and tracking probabilities above approximately 0.94-assuming common mode failures between the upper and lower tiers are negligible. If the attack is concentrated to saturate a single upper-tier site in a multisite architecture, then approximately $25 \%$ to $75 \%$ more interceptors are requried depending on the number of upper-tier sites needed for complete coverage and the maximum salvo launch threat. If CBW bomblets are part of the threat, then boost-phase TMD systems are required. Finally, if sophisticated decoys cannot be discriminated from warheads for either national or theater missile defense, the defense required to meet reasonable performance criteria grows linearly with the apparent attack size for barrage firing doctrines.

\section{APPENDIX: INTERCEPTOR REQUIREMENTS}

From Eqs. 5 and 11 one can derive the number of shots that must be fired at each incoming warhead to achieve a given level of defense effectiveness, $\mathrm{P}(0)$, if $\mathrm{W}$ warheads are in the attack. The parameters $k_{w}$ and $\mathrm{P}_{\mathrm{w}}$ (track) capture the technical performance of the defense. The result is

$$
\mathrm{n}=\frac{\ln \left(1-\frac{\mathrm{P}(0)^{1 / \mathrm{w}}}{\mathrm{P}_{\mathrm{w}}(\text { track })}\right)}{\ln \left(1-\mathrm{k}_{\mathrm{w}}\right)}
$$

This equation is valid whether decoys are present or not. In general, this equation yields non-integral values for the number of interceptors allocated to each incoming target, $n$. The integral value of $n$ that meets the defense effectiveness criterion is simply

$$
n^{*}=\operatorname{lnt}(n)+1
$$

where Int $(n)$ is the integer part of $n$.

However, a reasonable interpretation can be given for non-integer values of $n$, namely, some fraction of the incoming targets have I nt(n) interceptors allocated against them and the remainder have $\operatorname{lnt}(n)+1$. The fraction with $\operatorname{lnt}(\mathrm{n})+1$ interceptors equals the fractional part of $\mathrm{n}$ (i.e., $\mathrm{n}-\operatorname{Int}(\mathrm{n}))$. This interpretation is approximate as can be seen by recalculating Equation 5 with mixed interceptor allocations. The correct equation under these circumstances would be

$$
P(0)=K_{w i}^{(1-f)} W K_{w i+1}^{f W}
$$


where $K_{w i}$ is the warhead kill probability if i interceptors are fired at each of $(1-f) W$ targets, wheref is the fractional part of $n$, and $K_{w i+1}$ is the warhead kill probability if $\mathrm{i}+1$ shots are fired at the remainder. This can be reduced to

$$
P(0)=P(\text { track })^{W}\left[\left(1-I^{i}\right)^{1-f}\left(1-I^{i+1}\right)^{f}\right]^{W}
$$

from which one identifies

$$
\left\langle K_{w}\right\rangle=P_{w}(\operatorname{track})\left(1-I^{i}{ }_{w}\right)^{1-f}\left(1-I_{w}{ }^{i+1}\right)^{f}
$$

as the average warhead kill probability associated with a split interceptor allocation. Equation 11 is a reasonable approximation to Equation 17 for values of $n$ above 1.

\section{Barrage Firing Doctrine}

The number of BMD interceptors required to meet the defense performance criterion depends on the apparent size of the attack, i.e., W* in Equation 1, and the firing doctrine one assumes for the defense. The simplest doctrine is barrage fire ${ }^{32}$, where $\mathrm{n}$ interceptors are fired near simultaneously at each incoming target. The number of interceptors required for barrage fire, $I_{B}$, is simply

$$
\mathrm{I}_{\mathrm{B}}=\mathrm{W} * \mathrm{n}=\mathrm{W} *\left(\frac{\ln \left(1-\frac{\mathrm{P}(0)^{1 / \mathrm{W}}}{\mathrm{P}_{\mathrm{W}}\left(\operatorname{track}^{2}\right)}\right)}{\ln \left(1-\mathrm{k}_{\mathrm{W}}\right)}\right)
$$

Again, $P(0)$ is the desired probability that no warheads leak through the defense, $W^{*}$ is the apparent number of warheads in the attack, $W$ is the number of real warheads in the attack, $\mathrm{P}_{\mathrm{w}}$ (track) is the warhead detection, tracking, and discrimination probability, and $k_{w}$ is the interceptor SSPK against warheads. For barrage fire, the number of interceptors required increases linearly with the apparent attack size, provided the number of real warheads in the attack is fixed.

Equation 18 assumes that all interceptors can engage the incoming attack. This is true for a single BMD site with a footprint large enough to cover the territory of interest. It is also true if multiple BMD sites are required to cover the entire territory and the attack is spread uniformly across 
all defended footprints. However, if the attack is launched against targets located within a single BMD footprint of a multi-site system in an attempt to saturate the defense, then each BMD footprint must have $I_{B}$ interceptors. Therefore, to defend against attacks concentrated against a single site in a multi-site defense, a total of $m I_{B}$ interceptors must be deployed, where $\mathrm{m}$ is the number of BMD sites required for complete coverage. ${ }^{33}$

\section{Optimal shoot-look-shoot firing doctrine}

If shoot-look-shoot tactics are possible, fewer interceptors are required for equivalent defense effectiveness because the second shot(s) are directed only at those warheads and decoys that are not destroyed in the first shot opportunity. However, shoot-look-shoot is more demanding technically because it requires accurate kill assessment after the first shot opportunity and, typically, requires high-speed interceptors for reasonable defended footprints because less time is available for the second intercept attempt.

To simplify this calculation, the expected value for the number of apparent warheads leaking through the first shot opportunity is used. A more accurate calculation would use the probability distributions for the number of warheads and decoys classified as warheads that leak though the first shot opportunity. Using the expected value approach, the number of interceptors required assuming shoot-look-shoot tactics, $I_{S L S}$, is given by

$$
\mathrm{I}_{\mathrm{SLS}}(\mathrm{s})=\mathrm{sW} *+\left[\left(1-\mathrm{k}_{\mathrm{w}}\right)^{\mathrm{s}} \mathrm{P}_{\mathrm{ww}} \mathrm{W}+\left(1-\mathrm{k}_{\mathrm{d}}\right)^{\mathrm{s}} \mathrm{P}_{\mathrm{dw}} \mathrm{D}\right](\mathrm{n}-\mathrm{s})
$$

where s is an integer representing the number of shots taken at each apparent warhead in the first shot opportunity, $\mathrm{n}$ is the number of shots that must be taken at each warhead to achieve the defense performance criterion (given by Equation 12), and the other variables are defined earlier. This can be rewritten as the number of interceptors per apparent warhead as follows,

where

$$
\frac{\mathrm{I}_{\mathrm{SLS}}}{\mathrm{W}^{*}}=\mathrm{n}^{*}=\mathrm{s}+\left[\alpha\left(1-\mathrm{k}_{\mathrm{w}}\right)^{\mathrm{s}}+(1-\alpha)\left(1-\mathrm{k}_{\mathrm{d}}\right)^{\mathrm{s}}\right](\mathrm{n}-\mathrm{s})
$$




$$
\alpha=\frac{P_{w w} W}{\left(P_{w w} W+P_{d w} D\right)}
$$

is the fraction of apparent attacking objects that are warheads and $1-\alpha$ is the fraction of apparent attacking objects that are decoys. Frequently $s=1$, although minimizing $I_{S L S}$ may require s to be greater than 1 .

The optimal number of shots, $s_{o}$, in the first shot opportunity that minimizes $I_{S L S}$ can be determined from the following definition of the minimum value,

$$
\mathrm{n} *\left(\mathrm{~S}_{\mathrm{o}}+1\right) \geq \mathrm{n} *\left(\mathrm{~s}_{\mathrm{o}}\right) \leq \mathrm{n} *\left(\mathrm{~S}_{\mathrm{o}}-1\right)
$$

These inequalities can be reduced, after a bit of algebra, to the following inequalities,

$$
\mathrm{F}\left(\mathrm{n}, \mathrm{s}_{\mathrm{o}}\right) \leq 1 \leq \mathrm{F}\left(\mathrm{n}, \mathrm{s}_{\mathrm{o}}-1\right)
$$

where

$F(n, s)=\left(\left[\alpha k_{w}\left(1-k_{w}\right)^{s}+(1-\alpha) k_{d}\left(1-k_{d}\right)^{s}\right](n-s)+\left[\alpha\left(1-k_{w}\right)^{s+1}+(1-\alpha)\left(1-k_{d}\right)^{s+1}\right]\right)$

For a given value of $n, s_{o}$ can be found implicitly from the equation,

$$
\mathrm{F}\left(\mathrm{n}, \mathrm{S}_{\mathrm{o}}-1\right)=1
$$

The integral value for the optimal number of shots is simply Int $\left(\mathrm{s}_{\mathrm{o}}\right)$. If the interceptor SSPK is the same for decoys and warheads (i.e., $k_{w}=k_{d}$ ), or if decoys are not included in the attack (i.e., $\alpha=1$ ), the above equation reduces to,

$$
\left[k_{w}\left(n-s_{0}\right)+1\right]\left(1-k_{w}\right)^{s_{0}-1}=1
$$

Note that in this case the optimal interceptor allocation is independent of the apparent attack size, $W^{*}$. Hence, the number of interceptors required for the optimal shoot-look-shoot defense, $I_{S L S}$, is proportional to the apparent attack size for a fixed number of real warheads in the attack, assuming $k_{w}$ equals $k_{d}$ 
as the apparent attack size increases, as was the case for barrage firing doctrines.

Alternately, by picking an integral value for s, one can determine when the number of shots taken at each apparent warhead becomes large enough so the optimal number of shots taken in the first shot opportunity changes from s to $s+1$ (the subscript denoting the optimal value for $s$ has been dropped to simplify the formulas). ${ }^{34} \mathrm{~A}$ series of "transition" numbers, $n_{s}$, are thus obtained such that the optimal number of shots in the first shot opportunity is s provided that

$$
\mathrm{n}_{\mathrm{s}} \leq \mathrm{n}<\mathrm{n}_{\mathrm{s}+1}
$$

where $n_{s}$ is the solution to the equation

$$
\mathrm{F}\left(\mathrm{n}_{\mathrm{s}}, \mathrm{s}-1\right)=1
$$

for integral values of s. This approach has the advantage that Equation 23 can be solved explicitly for $n_{s}$ to give,

$$
n_{s}=(s-1)+\frac{1-\left[\alpha\left(1-k_{w}\right)^{s}+(1-\alpha)\left(1-k_{d}\right)^{s}\right]}{\left[\alpha k_{w}\left(1-k_{w}\right)^{s-1}+(1-\alpha) k_{d}\left(1-k_{d}\right)^{s-1}\right]}
$$

\section{Table 1}

Transition Numbers vs. Interceptor SSPK

\begin{tabular}{|llllllllll|}
\hline \multicolumn{2}{|c}{ Interceptor SSPK: } & & & & & & & \\
& 0.1 & 0.2 & 0.3 & 0.4 & 0.5 & 0.6 & 0.7 & 0.8 & 0.9 \\
\hline & & & & & & & & & \\
$\mathrm{n}_{1}$ & 1 & 1 & 1 & 1 & 1 & 1 & 1 & 1 & 1 \\
$\mathrm{n}_{2}$ & 3.11 & 3.25 & 3.43 & 3.67 & 4 & 4.5 & 5.33 & 7 & 12 \\
$\mathrm{n}_{3}$ & 5.35 & 5.81 & 6.47 & 7.44 & 9 & 11.75 & 17.44 & 33 & 113 \\
\hline
\end{tabular}


210 Wilkening

Again, if the interceptor SSPK is the same for warheads and decoys, or if no decoys are contained in the attack, this reduces to

$$
\mathrm{n}_{\mathrm{s}}=\mathrm{s}-\frac{1}{\mathrm{k}_{\mathrm{w}}}+\frac{1}{\mathrm{k}_{\mathrm{w}}\left(1-\mathrm{k}_{\mathrm{w}}\right)^{\mathrm{s}-1}}
$$

Table 1 gives the first four values of $n_{s}$ for different values of the interceptor SSPK, assuming decoys and warheads have the same SSPK. Practical defense systems rarely will fire more than five interceptors at an incoming target. Hence, the optimal shoot-look-shoot allocation rarely requires more than two shots in the first shot attempt. Non-integral values of $n_{s}$ are interpreted the same way as before, i.e., they provide the transition numbers that minimize Equation 19 given that s shots are taken in the first shot opportunity and the second shot opportunity has a split interceptor allocation with some targets having I $\mathrm{nt}(\mathrm{n}-\mathrm{s})$ interceptors and the remainder having I $\mathrm{nt}(\mathrm{n}-\mathrm{s}+1)$ interceptors allocated against them. If the interceptor SSPK against warheads and decoys is different, as may well be the case, then Equation 28 must be used to find the transition numbers.

\section{ACKNOWLEDG MENTS}

I would like to thank Steve Fetter, Geoffrey Forden, Lt. Gen. Glenn Kent (USAF ret.), J ulian Palmore, and Kevin Soo Hoo for commenting on various aspects of this work. In addition, I owe a special thanks to David Vaughan for suggesting some of the approaches taken in this paper. I also wish to thank the Center for I nternational Security and Cooperation, at Stanford University, and the Carnegie Corporation, without whose support this work would not have been possible. The views expressed herein are solely the author's.

\section{NOTES AND REFERENCES}

1. See The Ballistic Missile Defense Organization, Report to the Congress on Ballistic Missile Defense (Washington, D.C.: GPO, 1995): 3-3.

2. See M. Dornheim, "Missile Defense Design J uggles Complex Factors," Aviation Week and Space Technology(February 1997): 54.

3. Military forces can probably continue functioning if a few ballistic missiles armed with weapons of mass destruction land in their vicinity. Biological and chemical weap- 
ons, in particular, would largely be ineffective if troops wear protective gear. However, even one weapon of mass destruction landing on an allied city would be a threat greater than most allied leaders would tolerate.

4. Several countries (e.g., I ran, Syria, North Korea, Libya) reportedly have between 100 and 200 Scud-type short-range ballistic missiles in their current arsenals; however, the number of medium-range ballistic missiles is likely to be smaller over the next decade or two. Estimates between 50 and 200 medium-range ballistic missiles seem reasonable. I raq had approximately 220 Al Hussayn-type missiles and 11 Scud B missiles prior to the 1991 Gulf War, 88 of which were launched during the war, although they may have produced a total of approximately $400 \mathrm{Al}$ Hussayn missiles since the program's inception. See Timothy V. McCarthy, and J onathan B. Tucker, "Saddam's Toxic Arsenal: Chemical and Biological Weapons and Missiles in the Gulf Wars," In Planning The Unthinkable: New Powers and the Use of Nuclear, Biological, and Chemical Weapons, edited by Peter Lavoy, Scott D. Sagan, and J ames Wirtz. (Cornell University Press, 2000); and J ane's Strategic Weapons Systems(September, 1995): 19.

5. For a review of similar weapon-target allocation models, some of which include the number of weapons leaking through a defense, see S. Matlin, "A Review of the Literature On The Missile-Allocation Problem," Operations Research (1970): 18:334-373. In particular, optimal weapon-target allocation models that yield expected values for the number of warheads that penetrate the defense, assuming no decoys in the attack, are given in J .S. Przemieniecki, Mathematical Methods in Defense Analysis, 2nd Edition (Washington, D.C.: American Institute of Aeronautics and Astronautics,1994), 154159.; and N.K. J aiswal, Military Operations Research: Quantitative Decision Making (Boston: Kluwer Academic Publishers.1997), 169-172.

6. See B. Gertz, "N. Korean missile seen posing risk to U.S.," The Washington Times, September 16, 1998: 1.

7. See D.H. Rumsfeld, et al. Executive Summary of the Report of the Commission To Assess The Ballistic Missile Threat To The United States Pursuant to Public Law 201, 104th Congress (J uly 15 1998). (Available at: http://www.fas.org/irp/threat/bmthreat.htm).

8. Launch platform reliability would also be a common mode error if a single launch platform launches all the interceptors fired at the incoming targets. Otherwise, the launch reliability of the individual interceptors is included in the kill probability $\mathrm{Pj}$ (kill) no common mode failure). I ntermediate cases, where multiple launch platforms participate in the defense but several interceptors in a single engagement come from a single launch platform, are more complex and are not treated here. 
9. If a prior shot breaks a target into multiple pieces without actually destroying the warhead, for example, a Scud missile intercept where the empty fuel tank is cut in two but the warhead remains viable, then these equations must be modified to account for the extra target fragments (assuming the resulting fragments cannot be discriminated from the warhead after the failed intercept). This added complexity has been left out of this model.

10. For national missile defense, designers apparently hope for SSPKs around 0.85 . See Dornheim, M. 1997. Missile Defense Design J uggles Complex Factors. Aviation Week and Space Technology (F ebruary): 54 . For theater missile defense, the hoped for SSPK of the Theater High-Altitude Area Defense has been given as 0.80. See Teal Group Corporation, THAAD. World Missiles Briefing. (Fairfax: VA,1996). 6.

While optimistic, these numbers may not be totally unreasonable for unitary warheads, although one would expect the SSPK to drop in the presence of enemy countermeasures.

11. For example, a notional $10 \mathrm{~kW} X$-band $(\lambda=3 \mathrm{~cm})$ tracking radar with an effective antenna area of $10 \mathrm{~m}^{2}$ (this is a large power-aperture product, although less than the 3 million $\mathrm{W}-\mathrm{m}^{2}$ threshold that defines a large phased-array radar in the ABM Treaty) and a pulse repetition rate of $600 \mathrm{~Hz}$ could provide a detection probability of 0.999 against a target with an average radar cross section of $0.3 \mathrm{~m}^{2}$ at a range of $500 \mathrm{~km}$, with a false alarm rate of less than one per day. This assumes the target can be modeled as a Swirling Type 3 target and that the radar integrates 12 pulses (i.e., integrates for 0.02 seconds), is receiver noise limited with a noise figure of $2 \mathrm{~dB}$ and has total system losses less than $2 \mathrm{~dB}$. Such a radar would be able to establish a track with a probability above 0.99 for targets with a $0.3 \mathrm{~m}^{2}$ radar cross section up to $500 \mathrm{~km}$ away. See M. Skolnik, Introduction To Radar Systems, 2nd Edition (McGraw-Hill, 1980), 15-65.

12. Exoatmospheric intercepts occur above approximately $100 \mathrm{~km}$. Endoatmospheric intercepts occur at altitudes below approximately $80 \mathrm{~km}$. This distinction is important principally because simple lightweight decoys (balloons, chaff, etc.) are removed from the "threat cloud" at altitudes between 80 and $100 \mathrm{~km}$, thus reducing the decoy discrimination problem for ground-based BMD systems that conduct endoatmospheric intercepts. One should note that simple lightweight decoys are not effective on missiles with ranges less than about $350 \mathrm{~km}$ because these missiles never leave the atmosphere. For short-range missiles the opponent must design more sophisticated, heavier decoys or other penetration aids.

13. Explosive fragmentation warheads would work better against individual bomblets; however, existing U.S. upper-tier theater missile defenses (e.g., THAAD and NTW) only have hit-to-kill warheads.

14. Initial claims shortly after the Gulf War placed PAC-2 intercept performance at 
96 percent against I raqi Scud missiles. However, this estimate was lowered after critics challenged this assessment. Today, the Army claims that 40 percent of the Scuds aimed at I srael were successfully intercepted by PAC-2, where "successful intercept" is defined as an intercept that either destroys, damages, or knocks the warhead off course sufficiently to avoid damaging the intended target (with a unitary high-explosive warhead), and that 70 percent of the Scuds fired at Saudi Arabia were successfully intercepted. However, the Army also claims that only 25 percent of the intercepts destroyed the Scud warhead with "high confidence." On the other hand, a General Accounting Office investigation of these claims concluded that the available evidence only supports a 9 percent intercept rate, with the possibility that fewer than 9 percent of the Scud warheads were actually destroyed. See J. Conyers, J r., "The Patriot Myth: Caveat E mptor," Arms Control Today (November 1992):9; D. Bond, "Army Scales Back Assessments Of Patriot's Success in Gulf War," Aviation Week and Space Technology (April 1992): 64; G.N. Lewis, and T. A. Postol, "Video Evidence on the Effectiveness of Patriot during the 1991 Gulf War," Science \& Global Security, 4 (1993):1-63; and J . Sullivan, D. Fenstermacher, D. Fisher, R. Howes, O'D. J udd, and R. Speed, “Technical Debate over Patriot Performance in the Gulf War," Science \& Global Security, 8:1 (1999):1 - 57.

15. The Rumsfeld Commission recently pointed to weaknesses in the U.S. Intelligence Community's ability to accurately monitor ballistic missile development programs. Presumably this includes an opponent's countermeasure programs. While flight tests of modestly sophisticated countermeasures probably would be necessary, they may be difficult to observe -- recall the August 31, 1998 North Korean Taepo Dong-1 missile launch that attempted to put a satellite into orbit. The inability to determine whether this was a satellite launch, as North Korea originally claimed, or a ballistic missile test highlights the difficulty in providing the kind of accurate monitoring one would like to observe the development of countermeasures, especially for short and medium-range ballistic missiles, even when the U.S. Intelligence Community has advance notice of the launch.

16. See Uzi Rubin and Azriel Lorber, "Future Trend of Missile Proliferation in the Middle East and its Impact on Regional Missile Defense," American Institute of Aeronautics and Astronautics, (paper presented at the AIAA Conference on theater missile defense in London, England, 1995).

17. See Michael C. Sirak, "In NMD Test, Beacon Will Help Position EKV Until Booster Release," Inside Missile Defense5:9 (May 1999): 20.

18. See Michael C. Sirak, "DOD, Industry: NMD Countermeasures Getting Attention," Inside Missile Defense5:10 (May 1999):1.

19. Approximate methods for finding the optimal interceptor allocation between dif- 
ferent layers of a multi-layer defense are given in M.V. Finn and G.A. Kent. Simple Analytic Solutions To Complex Military Problems, N-2111-AF. Santa Monica, CA: RAND Corporation. (August 1985): 33-38.

20. See Michael C. Sirak, "BMDO:NMD 'C3' Architecture Could F eature U p to NineXband Radars," Inside Missile Defense5:10 (May 1999):13-14.

21. See Dean A. Wilkening, "ABM Treaty Compliance: Past Concerns and Future Debates," in eds., Michael Moody and Amy Sands, Compliance with Arms Control and Nonproliferation Agreements: Closing the Conceptual and Policy Gaps(forthcoming).

22. Taking a large number of shots at each incoming target stresses the NMD command and control system because each interceptor must be tracked as it flies toward the intercept point. In addition, if more than one NMD interceptor is maneuvering in the endgame, the latter interceptor's seeker may confuse the pervious interceptor with the target. Finally, the desire not to waste too many interceptors on early arriving targets in case subsequent attacks occur tends to limit the number of interceptors the defense will allocate to each target, assuming the attack is believed to be intentional.

23. The motivation for this example comes from the fact that two sophisticated decoys, along with other penetration aids, apparently were deployed on each Polaris SLBM warhead in the British Chevaline program during the 1980s to improve the penetration of the Moscow ABM system. See R. Norris, A. Burrows, and R. Fieldhouse, "British, French, and Chinese Nuclear Weapons," Nuclear Weapons Databook. Westview Press, V (1994):105-113.

24. See R. Shaver, "Priorities for Ballistic Missile Defense," in New Challenges for Defense Planning: Rethinking How Much Is Enough ed. Paul Davis. (Santa Monica, CA: RAND, 1994) 280-281.

25. See Department of Defense, Report to Congress on Theater Missile Defense Architecture Options for the Asia-Pacific Region(1999). Available at: http://www. fas.org/ spp/starwars/program/tmd050499.htm.

26. See Michael A. Dornheim, “Theater Wide' Missile Defense: Appealing, Controversial, Difficult," Aviation Week and Space Technology(1997): 62; and Department of Defense, Report to Congress on Theater Missile Defense Architecture Options for the Asia-Pacific Region, op cit.

27. See Teal Group Corporation, THAAD. World Missiles Briefing. (Fairfax: VA,1996). 6.

28. An estimate of 2-4 hours for the nominal Scud reload time is given by $T$. Cochran, 
W. Arkin, R. Norris, and J . Sands, Nuclear Weapons Databook, Vol. IV: Soviet Nuclear Weapons. (Washin gton, D.C: Natural Resources Defense Council,1989). 221

29. See J ane's Strategic Weapons Systems19 (September 1995); and D. I sby. J ane's Intelligence Review7:3 (March 1995):115-117.

30. Prior to the 1991 Gulf War I raq had approximately 220 Al Hussayn missiles and 14 mobile launchers (approximately 15 missiles per launcher). See V. McCarthy, B. Timothy and J onathan Tucker. Saddam's Toxic Arsenal: Chemical and Biological Weapons and Missiles in the Gulf Wars. In Planning The Unthinkable New Powers and the Use of Nuclear, Biological, and Chemical Weapons. Edited by Peter Lavoy, Scott D. Sagan, and J ames Wirtz. Cornell University Press, 2000. The maximum number of Al Hussayn's launched in a single day was 14 missiles (i.e., 6 percent of their arsenal), although the average daily launch rate dropped threefold (from 4.7 to 1.5 launches per day) after U.S. Scud-hunting operations began. See The Gulf War Air Power Survey, Summary Report 1:II. (Washington, DC: GOP, 1993) 84-87.

31. In general, the total number of interceptors that must be deployed to the theater to defend against concentrated attacks can be found by multiplying the number of interceptors given in Figure 7 by $(S+M-1) / M$, where $S$ is the number of TMD sites required for complete coverage and $M$ is the number of theater ballistic missiles per mobile launcher in the arsenal.

32. For a discussion of uniform (barrage), random, and shoot-look-shoot firing doctrines see J. S. Przemieniecki, Mathematical Methods in Defense Analysis, 2nd Edition.(Washington, D.C: American Institute of Aeronautics and Astronautics.1994), 154-159.

33. More complicated preferential offense and defense strategies can be considered. However, such modeling complexities do not alter appreciably the defense size one calculates using uniform attacks against uniform defenses. See N.K. J aiswal, Military Operations Research: Quantitative Decision Making(Boston: Kluwer Academic Publishers, 1997). 169-172.

34. This approach was originally suggested by David Vaughan. For a similar treatment, not including decoys, see E. Larson and G. Kent, A N ew Methodology for Assessing Multilayer Missile Defense Options MR-390-AF . (Santa Monica,

CA: RAND, 1994). 12-16 